\title{
Social Media Uses and their Perceived Outcome Satisfaction in the pre-Egyptian Revolt Context
}

\section{Nermeen Kassem, Ain-Shams University, Egypt}

Many commentators (i.e., Aouragh \& Alexander, 2011; Tufekci \& Wilson, 2012; Wilson \& Dunn, 2011; Wall \& Zahed, 2011) have remarked upon the role played by social media in the mobilisation that preceded the eruption of the massive demonstrations which took place in Egypt in early 2011, one of a number in the region that became known as the Arab Spring. This article was designed to address the question: "how do young Egyptian activists perceive the potential of social media for mobilising collective action?" The findings outlined in this article make a unique contribution to contemporary debates about social media and the Egyptian mobilisations, since the data was gathered prior to the uprising of $25^{\text {th }}$ January 2011. Consequently, it provides us with a clear understanding of what Egyptian activists actually thought and said about the potential value of social media, both for the organisation and the mobilisation of protests, rather than as retrospective judgments which may be subject to selective interpretations. This article highlights the perception trends of a sample of young Egyptian activists to whom the credit for igniting the two waves of uprisings $\left(25^{\text {th }}\right.$ January 2011 and $30^{\text {th }}$ June 2013) has been widely attributed. Data from questionnaires followed by focus group discussions indicate that young activists use social media as instruments to achieve their goals in order to inform and influence other non-politicised users' decisions, rather than being directed at achieving individualistic goals. Several limitations were also highlighted; some of which relate to the constituency, while others are mainly related to the media.

Keywords: social media, young activists, uses and gratifications (U\&G), mobilisation. 


\section{Introduction}

Political mobilisation that Egypt has witnessed over the last decade could be ascribed to a binary set of factors; the first set includes internal reasons and the second, external ones which are basically centred on pressures and incentives stemming from the international environment. Under U.S pressure to put the freedom agenda into effect (Tisdall, 2011), along with other internal and external stimuli, some Arab countries such as Egypt, Syria and Tunisia have seen the emergence of many new change movements at the beginning of the current decade. A number of these movements, including, for example, the Egyptian Movement for Change (EMC), known as 'Kefaya,' has managed to impose themselves strongly on the political arena, through promoting and implementing non-traditional theses among broad and important sectors of the community, which makes these movements an important variable in the political reality in these countries, and a phenomenon worthy of research and study.

In the social sphere, Egypt has witnessed significant developments that have had direct repercussions for political mobilisation. For example, the major development in the field of education and the eradication of illiteracy in the past two decades; the increasing rate of urbanisation; the growing role of women in society; prominent improvements in the health field, and the media boom. Among the main social factors is the contradiction between Egypt's socio-economic structure and developments arising from the growing sector of the younger generations who have studied abroad. These generations have accumulated a sense of alienation from their society, and desperation at the political elite's inability to achieve the goals of reform. Additionally, corruption in many sectors of the state has reflected on citizens' lives and has pushed them to despair of the possibility of solving their problems at the hands of the ruling regime. (Sha'ban, 2005).

In this article, a special focus is paid to politically-active young Egyptians and their active use of social media. The aim is to shed light on their evaluations of the role these media may have plaid in the emergence and development of these movements which led to the eruption of two waves of massive protests. The first wave broke out in $25^{\text {th }}$ January 2011 and led to the toppling of former President Mubarak, and the second erupted on $30^{\text {th }}$ June 2013, leading to the ousting of the elected President, Mohamed Morsi, after only a year in office. The aim is 
to better understand how these media might have contributed to creating opportunities for, or putting obstacles before, the development and growth of political mobilisation in Egypt over the past decade.

\section{Social Media Functions}

The last decade has witnessed a digital media boom that has significantly affected interest in the impact that information and communication technologies (ICTs) might have on several domains of life. This information revolution has particular implications on politics (DiMaggio, Hargittai, Neuman, \& Robinson, 2001) as it is creating an environment for political practice that is distinguished by being information-rich and communicationintensive (Bimber, 2001). It has been argued that studying motivation rather than impact (boyd, 2008), and patterns of use rather than gross hours of use (Shah, Kwak, \& Holbert, 2001) aids a better understanding of the potentials that certain modalities of media consumption hold for enabling political actions. The uses and gratifications (U\&G) perspective reinforces active images of audiences, specifying that individuals select and use media based on needs and on their perceptions of media attributes that might help to satisfy those needs. Social media have received a level of $U \& G$ attention. Albeit, this attention has by and large been focused on the general audience, usually college students who tend to be heavy users of social media (Cheung, Chiu, \& Lee, 2011; Liu, Cheung, \& Lee, 2010; Subrahmanyam, Reich, Waechter, \& Espinoza, 2008; Stoeckl, Rohrmeie, \& Hess, 2007). Few studies have applied the $U \& G$ rationale to politically interested Internet users (Kaye \& Johnson, 2002, 2004), and only a small, yet growing, body of studies have deployed the approach to explain how Internet users utilise social networking sites (SNSs) - in particular - to fulfill political needs (Leung, 2009; Cozma \& Ancu, 2009; Park, Kee, \& Valenzuela, 2009; Gary, Paul, \& Rekha Sharma, 2008).

The applicable studies of new media functions and their influence on individuals' political practices to date fall into two groups. Some researchers have looked at media uses in their relation to conventional political practices and to enhancing democracy that is focused primarily on voting and building social capital. A smaller, yet rapidly growing, body of research has investigated new media's potential for mobilisation and democratic transformation, which comprises the main focus of this article. 


\section{Media Uses and Protesting}

Social movement organisations and individual activists seem to be ardent adopters of new communication technologies (Bennett, 2003; van de Donk, Loader, Nixon, and Rucht, 2004). Functional categorisation of media uses, similar to those linked to political participation and civic engagement, has been linked, on a narrower scale, to social movement organisation and the mobilisation of unconventional collective practices. For example, in his critique of the Internet's and social media's potential to enhance democracy and undermine authoritarianism, Morozov (2012) distinguishes between the 'instrumental' and 'ecological' uses of social media. Instrumental uses, according to Morozov, mean that the Internet is just a neutral tool and an amplifier, and all that matters is how people utilise it to achieve good or bad ends. Ecological uses, on the other hand, mean that the Internet transforms both the environment where politics is made, and those who participate in politics (p. 8, 12).

It is inferred from Morozov (2012) and others' (e.g., Diani, 2000) that instrumental uses of media function differently in the realm of social movements. As instrumental uses imply a more active role of media users and so entail a positive association with political participation, instrumentality may help activists to achieve certain goals that are related to organising their movement and to creating positive dispositions that help the movement thrive. Yet, as compared to symbolic uses of media, using new media as a means to certain ends does not necessarily help to develop and sustain social movements as, compared to symbolic uses, they do not feed into building identities and developing feelings of commitment to movements. These different implications for social movements might have an impact on activists' evaluations of social media's contribution to movement development. To inquire into these assumptions, I start by asking the question:

RQ1: Why do young Egyptian activists use social media?

\section{Social Media Uses and Identification With and Commitment to Social Movements}

Unlike mass media, "social movements not only seek [audience] attention but also support and commitment" (Rucht, 2004, p. 33). Understanding how individuals identify with social movements has been increasingly discussed through the media lens (see, e.g. Castells, 2010; 
Pini, Brown, \& Previte, 2004; van Zoonen, 1992). Bennett (2005) concluded from his analysis of 705 cases around the February $15^{\text {th }}, 2003$, antiwar demonstrations in the U.S.A., that participants who relied most on the Internet and other digital media for their political information and communication were more likely to have strong identification with the global justice movement when compared to those who relied less on digital media or more on mass media, like TV, newspapers and radio. della Porta and Mosca (2005) found that activists in the anti-G8 protest in Genoa in July 200I and the European Social Forum (ESF) in Florence in November 2002 had used computer-mediated-communication (CMC) to develop what they called "non-virtual identities." Due to the Internet's capability to link distant and isolated individuals, it has been argued that the Internet fosters pluralist, open identities. Similarly, in his comparison between what he calls "direct action networks" and a more familiar model of organisationally brokered, ideological and issue-driven coalitions, Bennett (2005) concludes that using digital communication has allowed the diffusion of an organising code, or what is often termed "relationship-building", based on meta-frames such as diversity, inclusiveness, and social justice. This "relaxed framing", or what della Porta (2005) terms "tolerant identities", enables individuals with varied positions to join in remarkably large actions. In fact, the Internet has promoted a form of "individualised identities," an archetype of a networked society, that can nurture, discover and deploy creative forms of organisation through the Web (Castells, 1997).

As for commitment to movements, it has generally been suggested that research on social movements has raised some normative rather than instrumental constraints that influence different social movements' use of the media (della Porta, 2012, p. 52). A valid question here, then, is how these newly-formed, loose, manifold identities might reflect on social movements and the sustainable practice of collective action ${ }^{1}$. A range of empirical studies indicates that the digital media are unable to serve sustained collective action or to guarantee participants' commitment to social movement. The abundance of the alternatives of associations that are available online might foster low level of commitment that links individuals to such fluid structures. As Norris (2004) writes; "commitments to any particular online group can often be shallow and transient when another is but a mouse click away.

\footnotetext{
${ }^{1}$ It should be noted that these studies were conducted in the context of transnational protests, where diversity and flexibility are expected to emerge as a consequence of protesters heterogeneity (see also Walgrave \& Verhulst, 2009).
} 
Most purely online communities without any physical basis are usually low-cost, 'easy-entry, easy-exit' groups" (p. 4). della Porta rang the bells of "depoliticisation" and fragmentation due to social movements' comprehension as "particularist actors" (della Porta, 2012, p. 42). van Laer (2010) studied motivations to participate in collective action and Internet use by both online and off-line activists. He found that both instrumental motives and collective identity motives to participate in collective action only slightly drive activists' use of the Internet, i.e., the belief that something can be changed and that participation in demonstrations is an effective way to do so (instrumental motives), and participants' feeling of group belonging and-group solidarity do not significantly differ between off-line and online activists. van Laer has thus conversely suggested that using the Internet does not particularly fertilise stronger collective identity nor the perceived efficacy of collective action. Earl and Schussman (2002) earlier raised the problem of the strength of commitment to social movements. They contended that the rise of "e-activism" has created movement "users" rather than "members." They argue that while using the Internet has enabled the fast growth and wide spread of protests, this boom is usually followed by a faster decline in commitment. Along the same line, Garrett (2006) argues that technology-enabled additions to the repertoire of collective action might constrain the set of actions an activist can perform and may eventually formalise the role of activists and limit them. van Laer and van Aelst (2010), although confirming the role of the Internet in creating new opportunities for collective engagement, think that the Internet has made political action too easy, in some cases limiting the final impact of a certain action. As they write "it seems that the new media .... more fundamentally are unable to create stable ties between activists that are necessary for sustained collective action" (p. 1146). Using the Internet for political purposes might, then, result in a state of motivational dissonance; where participants have the motives for participation, yet these motivations might be spurred by media deficits such as ease of use or the lower cost of online practices. Individuals, therefore, may relent on online practices and prefer them to taking to the streets, which could hamper the sustainability of the political process, since it might not support the creation (or reinforcement) of significant participatory parameters such as collective identity and political efficacy.

Scholars also disagree about the potential of new communication technologies for empowering poorer people. While some emphasise a possible equalisation (Myers, 2002), others instead suggest either a neutral impact or the normalisation of political activity 
(Margolis \& Resnick, 2000), or even more concentration of power (McChesney, 1996). CMC seems to favour the elite over the masses, and it tends to reproduce the digital divide and hierarchy, and develops vertical relations instead of interactive, horizontal relationships (Rucht, 2003, p. 28). Rucht further suggests that "online activism could become a low-cost but also a low-effect substitute for off-line protest (p. 31).

These speculations about transcending traditional hierarchical models of social movement organisation lead to asking the question:

RQ2: How do young Egyptian activists evaluate the potential role of social media in mobilising collective action?

\section{Method}

This article uses data from questionnaires and focus group discussions (FGDs) to examine the questions asked. Respondents were recruited by a non-random sampling (non-probability sampling) technique where a sample of young Egyptian activists are selected purposively, based on the research objectives. Under the non-probability sampling umbrella, a snowball sample was accumulated for the purpose of this study. As the research objectives and research population are defined, no list of activists exists that might be used as a sampling frame that should contain all (or most) of the units of the population. Additionally, given the nature of this research and the context of the study, snowball-sampling is an appropriate technique for participant selection. Recommendations made by initial contacts are valuable in dealing with trust issues and in introducing the researcher to groups of activists who might otherwise be difficult to reach and who might refrain from discussing their political activities with strangers.

This study examined 367 responses from a self-administered survey that assessed activists' perceptions of social media's use for political communication. Certain attributes were selected to build the profile of respondents. According to the U\&G approach, the needs that individuals seek to satisfy are determined by their social environment, which includes their age, gender and group affiliation (Morris \& Ogan, 1996). Accordingly, the selected demographic variables correspond to certain issues in the Egyptian polity that are relevant to young Egyptians' geographical availability and related tendency to practise politics. Uses of social media were adapted from previous U\&G research (e.g., Kaye \& Johnson, 2004; Kim \& 
Kim, 2007). 'Networking' was added to the scale to allow respondents to indicate whether they use social media to build their own community of friends and aquaintances in order to reach a larger group of potential supporters with their mobilising messages. For each set of uses, Cronbach's $\alpha$ (alpha) was measured to determine the internal consistency of reliability of media uses test scores (Zinbarg, Revelle, Yovel, \& Li, 2005).

The gender ratio in the research sample is $39.8 \%$ male and $60.2 \%$ female $(n=362$, missing $=5)^{2} .64 .9$ percent are university students, $24.3 \%$ are university graduates, and only $8.2 \%$ hold higher degrees $(n=357$, missing $=10)$. Consistently, more than half of the participants fall into the age cohort between 18 and 22, while only $4.4 \%$ are between 30 and 35 years of age $(n=362$, missing $=5) .38 .1 \%$ of participants reported a monthly income range between 1000 and less than 3000 EGP. Equal proportions of respondents $(21 \%)$ reported that they earned between 3000 and less than 5000 EGP, and 5000 - 7000 EGP, and the smallest proportion of respondents fell into the higher income category of more than 7000 EGP ( $n=$ 346 , missing $=21$ ). Participants who expressed their willingness to take a further step in the research by providing their contact information in the questionnaire represented the sampling frame for the subsequent qualitative part of the research. Besides homogeneity and trust between members of each discussion group, selection from among willing respondents was directed by diversity in gender, age, income, and political background within the assigned homogenous groups, as revealed from preliminary analysis of the quantitative data. This yielded three complete FGDs with 20 participants and an average group size of seven participants. I made the choice to use participants' pseudonyms rather than revealing their real names as a precaution to assure their safety.

I used descriptive statistics to build up a profile of the participants. Frequencies were run on demographics, uses of social media, social media satisfaction. Mean and standard deviation were calculated to rank the social media use incentives participants reported. They describe the central location of the data and its spread, respectively. Qualitative data were analysed simply by listening repeatedly to discussions and transcribing them. Then I went over them several times to organise quotations and identify themes that emerge from activists' repertoires and correspond to each research question.

2367 participants completed the questionnaire for the current research. However, for some questions, some cases were missing and this explains the difference in the total number of research sample $(n)$ for some variables. 


\section{Results}

\section{Understanding what young activists use social media for}

Respondents indicated purposes for using social media on an index of 19 items that was split into six media usage categories: guidance, surveillance, networking, social utility, entertainment, and convenience, where 1 meant 'strongly disagree' and 5 meant 'strongly agree.'

Table 1 shows that information-related usage of social media ranked first across the media usage board. Politically active Internet users primarily used SOCIAL MEDIA for political guidance and surveillance and entertainment was the least significant reason for practicing political communication through social media.

Table 1: Young activists' usage purposes of social media

\begin{tabular}{lccc}
\hline Social media use constructs & Cronbach's $\boldsymbol{\alpha}$ & \multicolumn{2}{c}{ Factor Score } \\
\cline { 3 - 4 } & & Mean & SD \\
I use social networking sites for ... & & & \\
& & & \\
Guidance & 0.76 & 16.7 & 3.6 \\
\hline Surveillance & 0.68 & 16.2 & 2.4 \\
Convenience & 0.75 & 11.8 & 2.4 \\
\hline Networking & 0.67 & 11.1 & 2.3 \\
\hline Social utility & 0.65 & 7.7 & 1.5 \\
\hline Entertainment & 0.79 & 6.5 & 2.3 \\
\hline
\end{tabular}

The needs that activists sought to fulfill weighed differently in leading their active utilisation of the social media apparatuses. Figure 1 illustrates the proportional weight of each social media use construct as reported by the young activist participants.

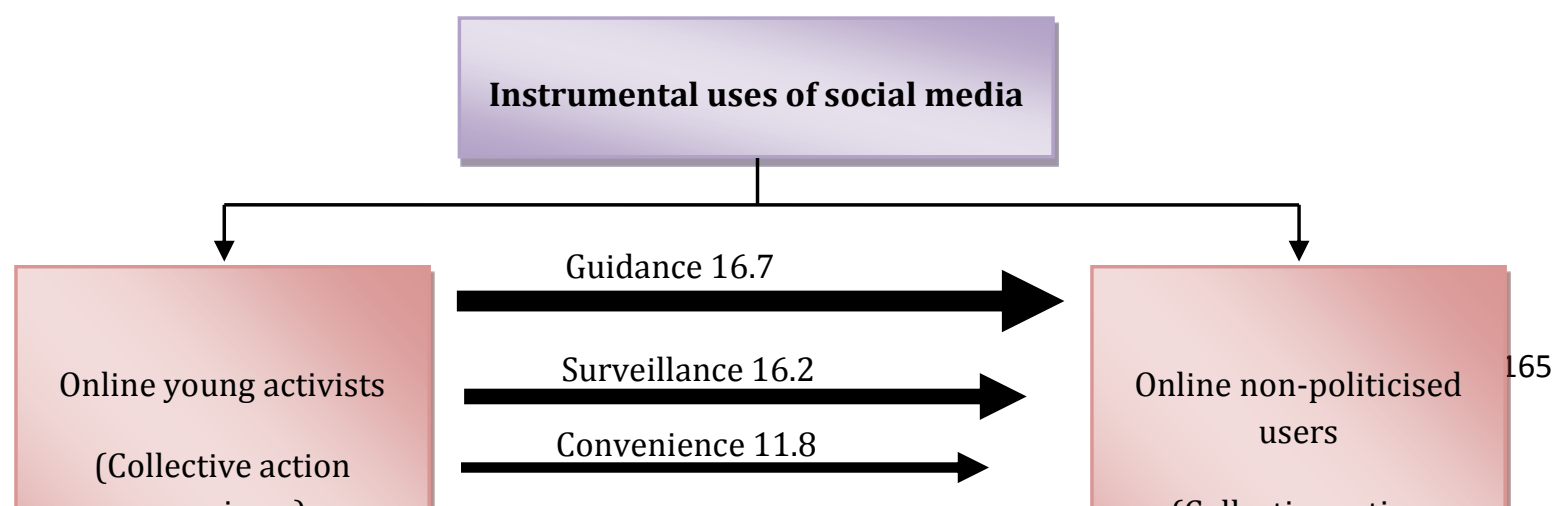


Table 2 shows in more detail the young activists'distribution by their social media uses. As appears from the Table, participant activists tend to agree more than to disagree that using social media for political communication helps them achieve certain goals relevant to their political activism. Using social media for giving advice about voting decisions is the only exception to this finding. The research sample is almost equally distributed between those who are not decided about $(35.4 \%)$ and those who disagree with $(35.1 \%)$ social media's potential as platforms where they can get political advice. Young activists seem not to perceive social media as suffecient tools for informing political decisions. This finding is discussed and explained in more details in Section 4.

\section{Informational Uses of Social Media}

Respondents indicated that they used social media for unbiased views and to decide on important issues. Guidance could be pursued by reviewing other users' comments on certain news stories. HA. expressed typical participants' views on the viability of electronic newspapers in making sense of the public sphere and informing activists' political decisions:

I always login to the websites of electronic newspapers like al Masry al Youm and read the readers' comments to build an impression of what people think and whether they are with or against posted news. When it comes to issues that concern public opinion, I think it is useful to visit those interactive websites to see how the collective thinks.

RA. agreed with HA.:

I also use websites like Masrawy and electronic newspapers for the reasons mentioned by HA.; to read people's comments and to know how the collective thinks. 

nor disagree

\begin{tabular}{llllllll}
\hline $\mathbf{F}$ & $\%$ & $\mathbf{F}$ & $\%$ & $\mathbf{F}$ & $\%$ & $\mathbf{F}$ & $\%$
\end{tabular}

\section{Guidance}

\begin{tabular}{|c|c|c|c|c|c|c|c|c|}
\hline To help me decide how to vote in the future. & 107 & 29.6 & 128 & 35.4 & 127 & 35.1 & 5 & 1.4 \\
\hline To help me decide about important issues. & 231 & 63.6 & 98 & 27 & 34 & 9.4 & 4 & 1.1 \\
\hline For unbiased viewpoints. & 194 & 54 & 121 & 33.7 & 44 & 12.3 & 8 & 2.2 \\
\hline $\begin{array}{l}\text { To help me convince others to vote in the next } \\
\text { election. }\end{array}$ & 127 & 35.9 & 118 & 33.3 & 109 & 30.8 & 13 & 3.5 \\
\hline To help other users decide on important issues. & 205 & 56.8 & 106 & 29.4 & 50 & 13.8 & 6 & 1.6 \\
\hline \multicolumn{9}{|l|}{ Surveillance } \\
\hline $\begin{array}{l}\text { To find specific political information for which I } \\
\text { am looking }\end{array}$ & 263 & 72.8 & 72 & 19.9 & 26 & 7.2 & 6 & 1.6 \\
\hline To keep up with main issues of the day. & 307 & 85.3 & 45 & 12.5 & 8 & 2.2 & 7 & 1.9 \\
\hline $\begin{array}{l}\text { Because it is an easy way to disseminate } \\
\text { information. }\end{array}$ & 315 & 87.5 & 38 & 10.6 & 45 & 12.5 & 7 & 1.9 \\
\hline $\begin{array}{l}\text { To help me draw other users' attention to certain } \\
\text { political information. }\end{array}$ & 233 & 65.3 & 90 & 25.2 & 34 & 9.6 & 10 & 2.7 \\
\hline \multicolumn{9}{|l|}{ Networking } \\
\hline $\begin{array}{l}\text { To join a group or groups that share the same } \\
\text { political interests with me. }\end{array}$ & 185 & 52.2 & 109 & 30.8 & 60 & 17 & 13 & 3.5 \\
\hline $\begin{array}{l}\text { Because it is an effective tool to reach a large } \\
\text { number of people. }\end{array}$ & 207 & 58 & 97 & 27.2 & 53 & 14.8 & 10 & 2.7 \\
\hline $\begin{array}{l}\text { Because it helps me organise political events on } \\
\text { a large scale. }\end{array}$ & 275 & 77.7 & 52 & 14.7 & 27 & 7.7 & 13 & 3.5 \\
\hline \multicolumn{9}{|l|}{ Social utility } \\
\hline To give me something to talk about with others. & 276 & 76.5 & 68 & 18.8 & 17 & 4.7 & 6 & 1.6 \\
\hline To use as ammunition in arguments with others. & 227 & 64.5 & 100 & 28.4 & 25 & 7.1 & 15 & 4.1 \\
\hline \multicolumn{9}{|l|}{ Entertainment } \\
\hline Because it is entertaining. & 203 & 56.8 & 78 & 21.8 & 76 & 21.3 & 10 & 2.7 \\
\hline Because it helps me relax. & 131 & 36.9 & 88 & 24.8 & 136 & 38.3 & 12 & 3.3 \\
\hline \multicolumn{9}{|l|}{ Convenience } \\
\hline $\begin{array}{l}\text { Because engaging in an online activity is less } \\
\text { time consuming. }\end{array}$ & 240 & 66.7 & 69 & 19.2 & 51 & 14.2 & 7 & 1.9 \\
\hline $\begin{array}{l}\text { Because engaging in an online activity is less } \\
\text { money consuming. }\end{array}$ & 272 & 76 & 58 & 16.2 & 28 & 7.8 & 9 & 2.5 \\
\hline Because I can get what I want with less effort. & 278 & 76.8 & 62 & 17.1 & 22 & 6.1 & 5 & 1.4 \\
\hline
\end{tabular}

Table 2: Young activists' distribution by social media uses 
Although social media may not be perceived as a primary source of news, since they were created primarily as platforms where friends could meet and connect, this finding is, on the one hand, consistent with previous research on Internet use for political information. For example, Kaye and Johnson (2004) found in their survey on politically-interested Internet users during the 2000 presidential election that users were primarily drawn to online sites for voting advice, followed by entertainment/social utility reasons, then convenience. Zhang et al. (2010) also found that $40 \%$ of general users of SNSs who participated in the survey had used MySpace and Facebook for political information. This might be explained by the time during which those studies were conducted; as Internet users are expected to utilise their preferred websites to fulfill needs relating to the presidential campaigns. Along the same lines, the current research was conducted at a time that witnessed significant political incidents, like the parliamentary election of November 2010; evolving sectarian clashes between Muslims and Christians, and the upcoming presidential election, which was due in September 2011, and which might have caused Internet users to seek political advice on certain issues. During such times, such incidents are expected to invigorate political discussions and heighten the debate about related issues, which might motivate individuals to seek political guidance in order to reach an opinion on certain matters.

On the other hand, another dimension of uses was added to the guidance factor in the questionnaire to reflect the interactive trait of social media. Interactivity entails the presence of other users and enables activists to influence potential supporters through their active, purposive use of media. This additional dimension might have pushed the guidance factor to the lead in social media uses schema as young activists aimed to influence others' political decisions. Participants believe that being able to guide and convince others is crucial for their mobilising efforts. H.B., typically, remarked:

Social media play a crucial role in our engagement and mobilising efforts; it gives us the space that traditional media suppress, and it hence enables us to reach those who do not take to the streets and have no other means to know what really happened there.

However, young activists think that only a small number of those who believe and trust in the content of the Internet would act accordingly. Yet this proportion, in A.Y.'s view, is sufficient to realise change and even to topple what he calls the 'aging regime:' 
The core of the mobilisation process is the capability to convince people. The Internet users can judge its content and choose whether to believe it or not. This level of trust and reliability is the determinant of whether a further action will be taken or not. In other words, if a million individuals read a certain statement on the Internet and did not believe it, they would not take action, but if they do believe it, we expect that an average of 10.000 will react to it. This is the way things happen, not all people move. But, I believe that the real value does not lie in the number in itself, rather, it lies in our credibility and our capability to mobilise people. If we can really mobilise $1 \%$ of the population, we can definitely make the 'ageing' regime fall.

Using social media to convince and mobilise others, rather than to inform young activists' political decisions, was supported by previous research. For example, Feezell, Conroy and Guerrero (2009) argue that "information is more likely to be reinforcing and therefore mobilising, but not enlightening and therefore educational" (p. 16).

Informational uses of social media, as revealed by survey data and participants' narratives, appear to follow two practices. The young Egyptian activists used social media to gather, generate, and disseminate what della Porta and Mosca (2005) called 'functional information' to serve informative, or what della Porta and Mosca (2005) termed 'cognitive', functions to expose the regime's misconduct and to circumvent national media's biased representations. They also used social media to disseminate technical information and relay certain participatory instructions to their supporters. These two dimensions of the informational uses of social media fall under the young activists' perceptions of social media as alternative platforms to the traditional, state-run media that are usually seen as unreliable, biased sources of information. They use social media to seek out, collect and diffuse 'non-mainstream' information (Dahlgren \& Olsson, 2009).

As for diffusing information (both informative and technical), several examples can be extracted from the FGDs. H.B. noted:

I think that social networking sites play a significant role as alternative media. It can be said that the traditional media outlets are blocked. It is also almost the same case even for the independent or the (opposition) press, which does not operate objectively 
or reveal facts as they are. Social networking sites could thus serve as ideologypromotion forums for certain movements. It has more credibility in broadcasting events.

Activists have been utilising social media as "primary sources" (Dahlgren \& Olsson, 2009, p. 202) for disseminating, rather than gaining, information. They uploaded first-hand information relevant to their activities that might differ from state-run media representations, or highlight a different angle of events. H.B. started by stating that he 'thinks' that SNSs are important alternative platforms that enable activists to deliver quality information that is more credible, reliable, and far reaching than the traditional media, which serve the terms of elite interests and allow no, or limited, space in which they can let their voices be heard. Moreover, social media not only substitute for state-run media, but also for independent media, which are supposed to present a different point of view but are still perceived as being unbalanced in their coverage.

The young activists' primary concern is to address others and illuminate areas that might be dimmed or smeared by other media sources. Direction is very significant in this regard, while previous studies have found that different uses of the Internet are mainly focused on gathering various kinds of information (i.e., Shah, Kwak, \& Holbert, 2001), participants in the current study stated that they used social media as a means to disseminate information. The young activists diffused informative messages to raise others' consciousness of certain incidents relevant to their activism. They also circulated technical information to achieve certain goals, like urging others to conduct certain course of actions, or giving instructions on how to particpate in certain events.

Using social media to address and mobilise others has benefitted activists in many ways. Immediacy of information delivery is an additional advantage that social media have afforded activists and, hence, it has enabled them to take timely informed decisions and act promptly. I.Z. typically asserted that:

The immediate delivery of information has advantaged us a lot in the first wave of the demonstrations we staged to support Khaled Said's cause in Lazoghly and in the march in Sherief Street ... .. The idea is that: such incidents should be published 
instantly on the Internet to draw people's attention and assert that the game is not yet over.

I.Z. made the point that activists used social media platforms to send a strong message to authorities and to challenge their manipulative ways of obliterating facts and enforcing certain agendas on the so-called 'national' media and, hence, on public opinion. Forcing certain content onto the mainstream media might result in reaching less technologically advantaged citizens. New media 'fluid' technologies may help citizens to interrupt the manipulated agenda of the national media to "support a greater variety of issue agendas and information access points" (Papacharissi, 2010, p. 120).

In such case, people tend to mistrust the 'national' media and to turn to the Internet as an alternative source of information (Tsfati, 2003; Tsfati \& Cappella, 2003).

Participants think that social media serve as on the run news portals that aggregate several sources of news on one portal for their rapid consumption. As W.B. remarked, "Facebook, of course, enables us to catch up with the news and interact with people promptly" especially when it comes to their activism and unconventional practices.

H.B., explained how Facebook was their main source of information about the massive demonstrations which broke out in Cairo's Shubra district in January $3^{\text {rd }} 2011$ to protest against the bombing of the Church of Saints in Alexandria (BBC, 2011):

The news I follow on Facebook completely differ from that I read in newspapers, and this is what happened in the Shubra demonstrations. Youths were beaten and kidnapped, albeit, al-Masry al-Youm newspaper only mentioned the damaged vehicles and some financial losses.

M.E. described how joining political groups on social media substitutes for traditional news media sources, especially when it comes to activists' dissident activities:

I joined the Khaled Said group [on Facebook] to know what happens in demonstrations because they post details on their page. The same applies to the April $6^{\text {th }}$ Movement, Justice and Freedom, and Socialist Reform groups. For example, there were demonstrations in Shubra, then we knew that some youths were arrested from a 
message sent on the group page. I join the largest number of groups to follow the news. They are like a newspaper to me (emphasis added).

Similarly, Hwang et al. (2006) found that antiwar opinion holders who felt that their views differed from those presented in mainstream media sought out alternative online sources for perspectives on the war. Perceptions of what has been termed "media dissociation" were argued to stimulate dissenters' information seeking and related political behaviours. On the other hand, social media benefitted participants' activism as means of distributing, rather than acquiring, information. A.Y. typically explained how using the Internet helped circumvent censorship and opened a window for the free expression of political opinion:

The reason why I insisted on launching my website on the Internet is that when I decided to write on politics, I found that all fronts of free speech were completely blocked, or allowed under certain conditions. And as I am not the kind of person who can bargain with his own beliefs to meet such conditions, or peel off his skin to satisfy people who control those opinion platforms, I decided from the very beginning to create my own platform where I could express my beliefs and relay my opinion the way I want at any time.

Social media have enabled activists to address wider audiences, whether directly through reaching out to potential supporters online, or indirectly via forcing their messages onto the traditional media agenda, or what could be termed the 'mediatisation' of the Internet, and hence, influence off-line audiences. Images and stories posted by bloggers and activists about police harassment and brutality were found efficient in spurring Egypt's mainstream media to cover the authorities' violations against citizens (Shapiro, 2009). For example, the case of the brutal murder of the young businessman, Khaled Said, was also taken to court after a photo of his mangled face was leaked from the mortuary and uploaded onto Facebook, which vehemently brought the cause to the focus of mainstream media and the broader public. This direction of information flow (Internet-mainstream) may be beneficial in a society with high rates of illiteracy and low levels of Internet penetration, as well as moderate levels of Internet self-efficiency, which makes mobilisation solely through social media a harder goal to achieve. For example, independent newspapers like al-Dustur have brought the Internet 
experience to readers without Internet access by re-printing the important weblogs on a special page (Shapiro, 2009).

Conversely, forming a bridge between traditional media content and new media platforms, or what has been labeled the "internetisation" of the media (Dahlgren, 2009, p.40), was found to afford activists a qualitatively wider platform from which to disseminate information, address public opinion and open certain topics up for debate. Equally, activists could conversely highlight selected mainstream media content and bring it to the consciousness of new media users. Cottle's (2011, p. 652) analysis brings him to a parallel conclusion:

New social media and mainstream media often appear to have performed in tandem, with social media variously acting as a watchdog of state controlled national media, alerting international news media to growing opposition and dissent events and providing raw images of these for wider dissemination.

\section{Social Media Satisfaction and Its Perceived Implications for the Mobilisation of}

\section{Collective Action}

The degree to which individuals are satisfied with a certain action influences their intentions to continue, stop or change the way they perform this action (Klandermans, 2004, p. 372). From a rational action perspective, individuals decide to practise and/or to continue practicing a certain action upon comparing the demands and supply of such an action. As for media use, the U\&G approach similarly suggests that users continue to use a certain medium based on the degree to which such a medium serves to gratify their pre-assessed needs (Papacharissi \& Rubin, 2000). It is to be expected, then, that such assessments of social media influence would reflect on young activists' future decisions about using social media to resource their activism and also about the goals which they utilise media tools to achieve. Participants were asked to indicate the extent to which they believe that social media are providing them with the things they are seeking. Table 3 shows young activists' distribution according to their reported feelings of satisfaction about social media's contribution.

Table 3: Young activists' distribution by social media satisfaction

$\begin{array}{lllll}\text { very Weakly to some } & \text { Strongly } & \text { Very } & \text { total }\end{array}$




\begin{tabular}{|c|c|c|c|c|c|c|c|c|c|c|c|c|}
\hline \multirow{2}{*}{$\begin{array}{l}\text { I'm satisfied with the } \\
\text { job social media do in } \\
\text { providing me with the }\end{array}$} & \multicolumn{4}{|c|}{ weakly } & \multicolumn{2}{|c|}{ extent } & \multicolumn{6}{|c|}{ strongly } \\
\hline & $F$ & $\%$ & $\mathrm{~F}$ & $\%$ & $\bar{F}$ & $\%$ & $\mathrm{~F}$ & $\%$ & $\mathrm{~F}$ & $\%$ & $\bar{F}$ & $\%$ \\
\hline $\begin{array}{l}\text { providing me with the } \\
\text { things I'm seeking ... }\end{array}$ & 14 & 3.9 & 68 & 18.7 & 195 & 53.7 & 69 & 19 & 17 & 4.7 & 363 & 100.0 \\
\hline
\end{tabular}

Missing: $\mathrm{F}=4(1.1 \%)$

As shown in the Table above, the majority of participant activists $(53.7 \%)$ are 'to some extent' satisfied with the job that social media deliver in terms of resourcing their political activism. Only $4.7 \%$ of the research population are very strongly" satisfied with social media's contribution.

As discussed in Section 4.2, influencing others' political decisions and disseminating information were the strongest reasons for the participant young activists use of social media. However, while there are several functions that social media contributed to achieving for young activists, data from FGDs also revealed that there are some aspects related to social media's influence on the young activists' movements, which they believe that social media did not necessarily contribute to gratification. Several themes about the perceived limitations of social media as tools for mobilising collective action emerged during the FGDs.

\section{Structural Fluidity and Defective Social Media Culture}

Young activists believe that there are several pitfalls that may dissolve their media-enabled mobilisation repertoire and, hence, deter social media's contribution to citizens' empowerment. The first deficit is related to the non-centralised organising structure of social media, which relates to the way users communicate over social media platforms, or what SO. termed a lack of social media culture. SO. suggested a convergent approach to better utilise social media affordances:

Utilising social networking sites for political mobilisation lacks two important aspects: a higher degree of organisation in regard to the way political activists use the medium, and a fundamental level of social media culture. I mean, how to supplement the use of a social media platform by convergence with other social media. For example, I can use Twitter as an add-on to Facebook, and improve practice by uploading related videos on YouTube ... .. I cannot expect efficient performance when 20 groups are created to discuss the same issues and to accomplish the same 
goals. We should create a system of alternative media that we can use when independent media channels and significant talk shows are suppressed. This will enable an autonomous institutional form of alternative media that can reach the broader public (emphasis added).

SO. believes that the polycentric organisation of the Internet results in structural fluidity. Thanks to the Internet, creating groups online has never been easier. Users can create groups online for all sorts of reasons which render some of these groups void of essence and meaningful influence. Instead of defective social media culture, SO. suggested a convergence culture that would fine-tune the focus of their message to their supporters.

Convergence culture allows for "the flow of content across multiple media platforms," (Jenkins, 2005, p. 2) and hence makes possible a holistic media experience and a stronger mobilising message. Providing multiple communicative cues was found to create a rich media experience in which immediate feedback, variety of language, and a personal focus are provided (Daft \& Lengel, 1986). Jenkins and Deuze (2008, p. 6) explain how shifts in media infrastructure have allowed grassroots to practise bottom-up consumer-driven processes of control that might circumvent traditional gatekeepers' and agenda setters' monopoly over the media.

Taking the lead from SO.'s views, M.S. added that social media's potential for empowerment could be raised by applying 'efficient economy of the Web:'

I believe that social networking sites could be the most important mobilising platform in Egypt if invested efficiently. ... .. As for the limited proportional numbers of those who take to the streets when compared to online supporters of a certain cause, I think this difference is due to the irrational use of the medium. Creating a group and inviting people to related events only because you are fascinated about a freak idea and want to aggregate people to come and applaud this idea, no matter how silly it is, will eventually mar the credibility of the source and the medium. Moreover, the abundance of groups will result in a disturbing glut of messages and notifications, which might lead users to abandon most of these groups (emphasis added). 
An abundance of online groups, in participants' points of view, might on the one hand polarise potential supporters, who would be stratified between multiple online groups that support the same cause. On the other, this structural fluidity of the Web would also put members of online groups off by the gush of messages they receive from these very similar groups. Taking a lead from SO.'s argument, M.S. suggests that similar groups should coordinate their efforts and mobilise for their cause harmoniously.

\section{Social Media's Perceived Credibility and Reliability}

Using social media as a means to influence others' decisions and to address them with certain information, rather than to inform activists' decisions and gain information, is thought to be the reason behind the precedence of informational uses of social media over other use factors. Participants expressed several views during the FGDs that support these inferences. It seems that relying on social media to support activists' own decisions does not explain much of participants' use of these media. Lack of social media's perceived credibility as a primary source of information was the most reported explanation for this finding during the FGDs. Recent research shows that perceived credibility is an essential parameter that guides the selection of different types of media sources for news consumption in an information-rich environment (Yuan, 2011). However, this significant condition does not apply to social media from the participants' points of view. The role that social media might play in stimulating, or enhancing, their political participation by "enabling them to encounter and make sense of events, relationships and cultures of which they have no direct experience" (Coleman \& Blumler, 2009, pp. 42, 43) was often criticised by young activists.

Activists think social media are reliable tools for disseminating functional information relevant to their activism. However, as primary sources of information, participant activists think that social media are less credible, less organised and, hence, less reliable sources of news compared to more traditional sources. W.B. started by telling that Facebook 'of course' is a valuable resource when it comes to keeping updated on current events and timely engagement with the content, as well as other users. He compared electronic newspapers and SNSs as sources of self-political guidance: 
Sometimes news presented on Facebook is not always accurate. It is more a kind of 'public journalism', this is why I sometimes find it more appealing to interact with, but when I seek more credible information, I log into electronic newspapers' websites which are more organised.

The young activists criticised social media as platforms for informing political discussions, for lacking professional mediation. Social media allow for political deliberation that is hardly "... .. mediated, with professional communicators rather than ordinary citizens talking to each other and to the public through mass media of communications" (Page, 1996, p. 1). This means that for the politically experienced citizens, social media are not perceived in and of itself as an efficient arena for comprehending the political sphere. They realise social media's deficiencies in terms of offering a "central organising idea or story line that provides meaning to an unfolding strip of events [and a coherent frame that] suggests what the controversy is about, the essence of the issue" (Gamson \& Modigliani, 1987, p. 143). They believe that news frames are better presented on the electronic newspapers, where journalists can identify and classify information and "package it for efficient relay to their audiences" (Gitlin, 2003, p. 7). More recent research shows that reliability is one of the problems that computermediated-communication raises within social movements (e.g., Rucht 2003). Clark and Themudo (2003) arrived at a similar conclusion. They argue that Internet campaigns have "inherently weak mechanisms of information quality control," and the "Internet is a better medium for disseminating information and opinions than for building trust, developing coherence and resolving controversies" (p. 114).

Accordingly, participants tend to selectively consume news on social media as they stressed the importance of dealing cautiously with social media as primary news sources, and the necessity to consume their content through a critical lens. A.Ma. cited several reasons for preferring electronic newspapers over Facebook as a platform for gaining constructive political guidance:

Electronic newspapers are more organised than Facebook. Writers have certain ideas that they discuss, and users who post comments on the news stories show a level of awareness. 
Participants think that political discussions on social media platforms are polarised, which makes it harder for media users to follow these discussions and extract valuable information from them. Similarly, Johnson and Kaye (2010) found in the study they conducted during the 2004 U.S.A. presidential election that politically interested Web users perceived all online media as being only moderately credible. It was also found that news gathered from SNSs, like MySpace, Facebook, and YouTube, did not add much to users' political knowledge or to democratic discourse when compared with the impact of using other news sources, like cable news and traditional media (Baumgartner \& Morris, 2010). Along the same lines, Thelwall (2008) concluded from his comparative exploratory study of SNSs and weblogs that news has no place on the former. A.A. discussed what the participants meant by organisation:

I think that Twitter, Facebook, and the like are 'illusory spaces.' They are far from reality, compared to electronic newspapers and, hence, less effective. I feel that electronic newspapers are more serious. People who write in these newspapers are basically writers and journalists, thus they are politicised and the posted comments and feedback on their work are almost at the same level. But on social networking sites and blogs, the situation is a bit chaotic and not goal-directed, which evokes questions about its genuine political value (emphasis added).

A.A. is doubtful about the political efficacy of social media in terms of acquiring information. He delineates the aspect of organisation and how it affects activists' tendency to use social media as sources of information. For A.A., social media are misleading and 'far from reality' when compared to electronic newspapers. Discussions on social media do not follow a certain theme and they lack professionalism, which affects the quality of discussions on these platforms and may cause polarisation, rather than developing the communicative exchange. This obscuring divergence of online discussions was ascribed to the nature of the digital world as a fragmented, hyper-pluralistic space. Heterogeneity and disagreements are expected to arouse cognitive dissonance which, again, feeds into more withdrawals from discussions, as "to avoid cognitive dissonance, it is simpler to exit than to work through any messy bargaining and conflictual disagreements within the group" (Norris, 2004, p. 4).

\section{Social Media and the Perceived Erosion of the Off-Line Practice of Collective Action}


SO. argued that utilising aggregate media portals helped activists build a favourable participatory disposition among individuals, or what SO. called public status and thus enabled them to mobilise action on a larger scale. He typically remarked:

By [converging several social media platforms] we might be capable of creating a desirable public status that could encompass a larger number of youth and incentivise them to participate. These platforms should thus work in concert with each other.

However, young activists think that social media has a limited capacity to breach the borders of the virtual sphere and extend the mobilising effect to the off-line arena. A.A., typically, explained:

I think the main problem is that practising politics in Egypt is still immature, this is why people tend to practise virtual political activism. I mean, if there was real political participation, people would not have spent their time chatting. Rather, they would take to the streets and play the role properly. For example, when the Kefaya (Enough) movement first started, we had 1500 registered members online, but how many were actually on the streets? In fact, you barely find 150 or 200 protesters in any protest (emphasis added).

Similarly, Smitten (2008) argues that although the Internet has leverages that may enable online communities to act politically, there are also limitations that can make the "..... predominant effect of political action of online communities [is] the arousal of public attention as a sign of successful articulation of interests" (p.51). Some political online communities, according to Smitten, lack organisation around well-defined political objectives, and even if they assess those objectives, they may face the difficulty of accessing the political system, especially in dictatorships and non-pluralist societies. This may impose difficulties on bridging online activism to the off-line context to make social and political change feasible. Additionally, the inner structure of online communities does not follow a certain law of organisation. The aforementioned non-centralised form of Internet organisation poses questions on the quality of the "decision-making" and "policy-formation" of these communities and serves as a justification for taking them lightly in the political arena. (Smitten, 2008, p. 51). boyd further (2008) argues that activists are not being realistic in their evaluations of the potential of SNSs for empowering ordinary citizens. 
Although social media have provided activists with more convenient tools of organisation and participation, as individuals practicing politics, conveniently they may run the risk of perceiving themselves to be active participators or political players, while they are actually debating about politics rather than taking part in it. Participants believe that practising politics on soial media platforms may erode actual participation and limit collective action to the virtual sphere. Relying on Jenkin's notions about media convergent culture, drawing an analogy between Jenkin's notions about the influence of media convergence on media use (new and traditional) and participants' perceptions of the influence of on- and off-line mashups on political practice (virtual and real), delineates participant activists' views about proportional differences between online interactors and off-line actors. Jenkins (2005, p. 6) argues that:

On the one hand, convergence represents an expanded opportunity, since content which succeeds in one sector can spread across other platforms. On the other, convergence represents a risk since once you move filmgoers from theaters to cells one wonders if they will return again.

Similarly, it can be said that once you move protesters from streets to social media one wonders if they will return again. Based on the results discussed hitherto, Table 4 summarises social media's perceived deficiencies in relation to different categories of media use.

Table 4: Uses of social media and their perceived deficiencies

\begin{tabular}{|c|c|}
\hline Social media uses & Social media's perceived deficiencies \\
\hline $\begin{array}{l}\text { Social media for } \\
\text { guidance }\end{array}$ & Organisation fluidity and disparity of online groups \\
\hline $\begin{array}{l}\text { Social media for } \\
\text { surveillance }\end{array}$ & $\begin{array}{l}\text { - Non-reliable primary source of information } \\
\text { - Selective credibility of functional information }\end{array}$ \\
\hline $\begin{array}{l}\text { Social media for } \\
\text { convenience }\end{array}$ & $\begin{array}{l}\text { - Illusory space of practice } \\
\text { - Eroding off-line collective practice }\end{array}$ \\
\hline $\begin{array}{l}\text { Social media for } \\
\text { networking }\end{array}$ & $\begin{array}{l}\text { Irrational utilisation resulting in multi-structural basis of social } \\
\text { movement and glut of online group formation and content } \\
\text { production }\end{array}$ \\
\hline Social media for & Non-thematic deliberation leading to the obscuring of meanings and \\
\hline
\end{tabular}




\section{Conclusion: young Egyptian activists and the instrumentality of social media}

The aim of this study is to understand what drives young Egyptian activists' use of the apparatuses of social media for their political activism, and how they evaluate media's contribution to gratifying their sought goals. The findings revealed several needs that young Egyptian activists use social media as instruments to achieve. These goals are more directed at disseminating information in order to inform and influence other non-politicised users' decisions, rather than being directed at achieving individualistic goals. This is evident from activists' critique of social media affordances and their perceived influence in fulfilling activists' pre-assessed needs.

Those underpinnings of media use were found to be moderated by activists' perceptions of social media as being 'somewhat' reliable sources of information. Censorship also emerged as an incentive to information seeking and dissemination purposes. The results confirm that young Egyptian activists are only moderately satisfied with the political outcome that can be achieved from social media use. Some central themes emerged in the current difficulties facing mobilisation through the purposive use of social media as perceived by young Egyptian activists. It could be said that while there have been some interesting changes in the way activism is practised, especially in terms of disseminating information and aggregating support at lower price, yet the importance of social media is modest. Digital social networks are not deemed yet to be a factor of mobilisation. Young activists realise that using social media for mobilising collective action suffers a number of deficits both on the user and the medium sides. Such deficits may limit the impact, if any, of activists' online political efforts. The argument is that the way social media are currently utilised, especially by the nonpoliticised, may cause polarisation rather than aggregation. Media dissatisfaction is expected hence, to have its impact on users' decisions to continue, stop using or to alter the way they utilise these platforms to better achieve political change.

This study contributes to understanding the escalating allegations about the contribution of social networking sites to provoking collective action and therefore to realistically addressing claims about 'Facebook and Twitter revolutions.' It also delineates the perceived difference between activists and non-activists in terms of needs that social media may contribute to 
fulfilling. Accordingly, this study suggests that young activists need to deploy a number of best practice tactics and know how strategies that may help them overcome social media deficits and better approach potential supporters.

\section{References}

Aouragh, M., \& Alexander, A. (2011). The Egyptian Experience: Sense and Nonsense of the Internet Revolution. International Journal of communication, 5(1), 1344-1358.

Baumgartner, J. C., \& Morris, J. S. (2010). MyFaceTube Politics: Social Networking Web Sites and Political Engagement of Young Adults. Social Science Computer Review, 28 (1), 24-44.

BBC. (2011, January 4). Protests Erupt in Egypt Against Bombing the Saints Church in Alexandria. Retrieved February 2011, from BBC Arabic: http://www.bbc.co.uk/arabic/middleeast/2011/01/110104_church_riots.shtml

Bennett, W. L. (2003). Communicating Global Activism: Strengths and Vulnerabilities of Networked Politics. Information, Communication \& Society, 6 (2), 143-168.

Bennett, W. L. (2005). Social Movements Beyond Borders: Organisation, Communication, and Political Capacity in Two Eras of Transnational Activism. In D. d. Porta, \& S. 
Tarrow, Transnational Protest and Global Activism: People, Passions, and Power (pp. 203-226). Oxford: Rowman \& Littlefield Publishers.

Bimber, B. (2001). Information and Political Engagement in America: The Serach for Effect of Information Technology at the Individual Level. Political Research Quarterly, 45 (1), 53-67.

boyd, D. (2008). Can Social Network Sites Enable Political Action? In M. S. Allison Fine, Rebooting America (pp. 112-116). Creative Commons.

Castells, M. (2010). The Power of Identity: The Information Age: Economy, Society, and Culture Volume II. Wiley-Blackwell.

Castells, M. (1997 ). The Power of Identity. Oxford: Blackwell.

Cheung, C. M., Chiu, P.-Y., \& Lee, M. K. (2011). Online Social Networks: Why Do Students Use Facebook? Computers in Human Behavior, 27 (4), 1337-1343.

Clark, J., \& Themudo, N. (2003). The Age of Protest: Internet-based 'Dot Causes' and the 'Anti-Globalization' Movement. In J. Clark, Globalising Civic Engagement. Civil Society and Transnational Action (pp. 109-126). London: Earthscan.

Coleman, S., \& Blumler, J. G. (2009). The Internet and Democratic Citizenship: Theory, Practice and Policy. Cambridge University Press.

Cozma, R., \& Ancu, M. (2009). MySpace Politics: Uses and Gratifications of Befriending Candidates. Journal of Broadcasting and Electronic Media, 53 (4), 567-583.

Daft, R. L., \& Lengel, R. H. (1986). Organisational Information Requirements, Media Richness and Structural Design. Management Science, 32 (5), 554-571.

Dahlgren, P. (2009). Media and Political Engagement: Citizens, Communication, Democracy. New York: Cambridge University Press.

Dahlgren, P., \& Olsson, T. (2009). From Public Sphere to Civic Culture. Young Citizens Internet Use. In I. R. Butsch (Ed.), Media and Public Spheres, 198-209. Basengstoke: Palgrave Macmillan.

della Porta, D. (2012). Communication in Movement: Social Moements as Agents of Participatory Democracy. In B. D. Loader, \& D. Mercea, Social Media and Democracy : Innovations in Participatory Politics (pp. 39-53). London: Routledge.

della Porta, D., \& Mosca, L. (2005). Global-Net for Global Movements? A Network of Networks for a Movement of Movements. Della Porta, Donatella, and Lorenzo Mosca. "Global-Net for Global Movements? Journal of Public Policy, 25 (1), 165190. 
Diani, M. (2000). Social Movement Networks Virtual and Real. Information, Communication \& Society, 3 (3), 386-401.

DiMaggio, P., Hargittai, E., Neuman, W. R., \& Robinson, J. P. (2001). Social Implications of the Internet. Annual Review of Sociology, 27, 307-336.

Earl, J., \& Schussman, A. (2002). The New Site of Activism: On-Line Organisations, Movement Entrepreneurs, and the Changing Location of Social Movement Decision Making. Research in Social Movements, Conflicts and Change, 24, 155-187.

Feezell, J., Conroy, M., \& Guerrero, M. (2009). Facebook is... Fostering Political Engagement: A Study of Online Social Networking Groups and Offline Participation. Paper Presented at The American Political Science Association Meeting. Toronto, Canada.

Gamson, W. A., \& Modigliani, A. (1987). The Changing Culture of Affirmative Action. In R. G. Braungart, \& M. M. Braungart, Research in Poilitical Sociology (pp. 137-177). Greenwich, CT: JAI.

Garrett, R. K. (2006). Protest in an Information Society: A Review of Literature on Social Movements and New ICTs. Information, Communication \& Society, 9 (2), 202-224.

Gitlin, T. (2003). The Whole World is Watching: Mass Media in the Making and Unmaking of the New Left. Berkeley: University of California Press.

Hanson, G. L., Haridakis, P. M., \& Sharma, R. (2011). Differing uses of YouTube during the 2008 US presidential primary election. Electronic News,5(1), 1-19.

Hwang, H., Schmierbach, M., Paek, H.-J., Zuniga, H. G., \& Shah, D. (2006). Media Dissociation, Internet Use, and Antiwar Political Participation: A Case Study of Political Dissent and Action Against the War in Iraq. Mass Communication \& Society, 9 (4), 461-483.

Jenkins, H. (2005). Welcome to Convergence Culture. Receiver, 2.

Jenkins, H., \& Deuze, M. (2008). Convergence Culture. Convergence: The International of Research into New Media Technologies, 14(1), 5-12.

Johnson, T., \& Kaye, B. (2010). Choosing is Believing? How Web Gratifications and Reliance Affect Internet Credibility Among Politically Interested Users. Atlantic Journal of Communication, 18(1), 1-21.

Kaye, B. K., \& Johnson, T. J. (2004). A Web for all Reasons: Uses and Gratifications for Internet Components for Political Information. Telematics and Informatics, 21, $197-$ 223. 
Kaye, B. K., \& Johnson, T. J. (2002). Online and in the Know: Uses and Gratifications of the Web for Political Information. Journal of Broadcasting \& Electronic Media, 46 (1), 54-77.

Klandermans, B. (2004). The Demand and Supply of Participation: Social-Psychological Correlates of Participation in Social Movements. In D. A. Snow, S. A. Soule, \& H. Kriesi, The Blackwell Companion to Social Movements (pp. 360-379). Blackwell Publishing.

van Laer, J. (2010). Activists Online and Offline: The Internet as an Information Channel for Protest Demonstrations. Mobilisation: An International Quarterly, 15 (3), 347-366.

van Laer, J, \& van Aelst, P. (2010). Internet and Social Movement Action Repertoires: Opportunities and Limitations. Information, Communication \& Society, 13 (8), $1146-$ 1171.

Leung, L. (2009). User-Generated Content on the Internet: An Examination of Gratification, Civic Engagement and Psychological Empowerment. New Media \& Society, 13271347.

Liu, I. L., Cheung, C. M., \& Lee, M. K. (2010). Understanding Twitter Usage: What Drive People Continue to Tweet. PACIS, 928-939.

Margolis, M., \& Resnick, D. (2000). Politics as Usual. The Cyberspace 'Revolution'. Thousand Oaks, CA: SAGE Publications.

Morozov, E. (2012). The Net Delusion: The Dark Side of Internet Freedom. PublicAffairs, 126.

Morris, M., \& Ogan, C. (1996). The Internet as Mass Medium. Journal of ComputerMediated Communication, 1 (4).

Myers, D. J. (2002). Social Activism Through Computer Networks. In O. V. Burton, Computing in the Social Sciences and Humanities (pp. 124-139). Urbana, IL: University of Illinois Press.

Norris, P. (2004). The Bridging and Bonding Role of Online Communities. Thousand Oaks, California: SAGE Publications.

Page, B. I. (1996). Who Deliberates? Mass Media in Modern Democracy. Chicago: University of

Chicago Press. 
Papacharissi, Z. (2010). A Private Sphere : Democracy in a Digital Age. Cambridge: Polity Press.

Papacharissi, Z., \& Rubin, A. M. (2000). Predictors of Internet Use. Journal of Broadcasting \& Electronic Media, 44 (2), 775-196.

Park, N., Kee, K. F., \& Valenzuela, S. (2009). Being Immersed in Social Networking Environment: Facebook Groups, Uses and Gratifications and Social Outcomes. Cyber Psychology \& Behavior, 12 (6), 729-733.

Pini, B., Brown, K., \& Previte, J. (2004). Politics and Identity in Cyberspace. In W. v. Donk, B. D. Loader, P. G. Nixon, \& D. Rucht, Cyberprotest: New Media, Citizens nd Social Movements (pp. 259-274). London: Routlege.

Rucht, D. (2003). Media Strategies and Media Resonance in Transnational Protest Campaigns. Transnational Processes and Social Movements. Bellagio, Italy.

Rucht, D. (2004). The Quadruple 'A': Media Strategies of Protest Movements Since the 1960s. In W. van de Donk, B. D. Loader, P. G. Nixon, \& D. Rucht, Cyberprotest: New Media, Citizens and Social Movements (pp. 29-56). London: Routledge.

Sha'ban, A. B.-d. (2005). Political Mobilisation in the Region: Manifistations, Justifications, Trends, Dimensions and Prospects (in Arabic). Arabic Affairs (123), 13-14.

Shah, D. V., Kwak, N., \& Holbert, R. L. (2001). "Connecting” and "Disconnecting” With Civic Life: Patterns of Internet Use and the Production of Social Capital. Political Communication, 8 (2), 141-162.

Shapiro, S. M. (2009). Revolution, Facebook-Style. The New York Times, 1-9.

Smitten, S. I. (2008). Political Potential and Capabilities of Onlie Communities. German Policy Studies, 4 (4), 33-62.

Stoeckl, R., Rohrmeie, P., \& Hess, T. (2007). Motivations to Produce User Generated Content: Differences Between Webloggers and Videobloggers. 20th Bled eConference: eMergence: Merging and Emerging Technologies, Processes, and Institutions, (pp. 398-413). Bled, Slovenia.

Subrahmanyam, K., Reich, S. M., Waechter, N., \& Espinoza, G. (2008). Online and Offline Social Networks: Use of Social Networking Sites by Emerging Adults. Journal of Applied Developmental Psychology, 29 (6), 420-433.

Thelwall, M. (2008). No Place for News in Social Network Web Sites? Online Information Review, 32 (6), 726-744. 
Tisdall, S. (2011, February 11). Hosni Mubarak: Egyptian 'Pharaoh' Dethroned Amid Gunfire and Blood. Retrieved February 2011, from The Guardian: http://www.theguardian.com/world/2011/feb/11/hosni-mubarak-resigns-analysis.

Tsfati, Y. (2003). Media Skepticism and Climate of Opinion Perception. International Journal of Public Opinion Research, 15 (1), 65-82.

Tsfati, Y., \& Cappella, J. N. (2003). Do People Watch What They Do not Trust? Exploring the Association Between News Media Skepticism and Exposure. Communication Research, 30 (5), 504-529.

Tufekci, Z., \& Wilson, C. (2012). Social media and the decision to participate in political protest: Observations from Tahrir Square. Journal of Communication, 62(2), 363-379.

van de Donk, W., Loader, B. D., Nixon, P. G., \& Rucht, D. (2004). Cyberprotest: New media, Citizens and Social Movements. London: Routledge.

van Zoonen, E. A. (1992). The Women's Movement and the Media: Constructing a Public Identity. European Journal of Communication, 7(4), 453-476.

Yuan, E. (2011). News consumption across multiple media platforms: A repertoire approach. Information, Communication \& Society, 14(7), 998-1016.

Zhang, W., Johnson, T. J., Seltzer, T., \& Bichard, S. L. (2010). The Revolution Will be Networked: The Influence of Social Networking Sites on Political Attitudes and Behavior. Social Science Computer Review, 28 (1), 75-92.

Zinbarg, R. E., Revelle, W., Yovel, I., \& Li, W. (2005). Cronbach's $\alpha$, Revelle's $\beta$, and McDonald's $\omega \mathrm{H}$ :Their Relations With Each Other and Two Alternative Conceptualizations of Reliability. Psychometrika, 70 (1), 123-133. 